\title{
The effects of supplementation with omega-3 polyunsaturated fatty acids on cardiac rhythm: anti-arrhythmic, pro-arrhythmic, both or neither? It depends...
}

\author{
Bernhard Rauch $^{1}{ }^{*}$ and Jochen Senges ${ }^{2}$ \\ ${ }^{1}$ Zentrum für Ambulante Rehabilitation am Klinikum der Stadt Ludwigshafen, Ludwigshafen am Rhein, Germany \\ 2 Institut für Herzinfarktforschung Ludwigshafen an der Universität Heidelberg, Ludwigshafen am Rhein, Germany
}

\section{Edited by:}

George E. Billman, The Ohio State

University, USA

Reviewed by:

Ruben Coronel, Academic Medical Center Amsterdam, Netherlands

Peter Van Dam, UMC Nijmegen,

Netherlands

Bill Harris, Health Diagnostic

Laboratory, USA

Clemens Von Schacky, Ludwig

Maximilians University Munich,

Germany

\section{*Correspondence:}

Bernhard Rauch, Zentrum für

Ambulante Rehabilitation am Klinikum

der Stadt Ludwigshafen, Bremserstr.

79, D-67063 Ludwigshafen am Rhein,

Germany.

e-mail: rauch@zar-kardio-

ludwigshafen.de

\begin{abstract}
Supplementation of omega-3 fatty acids $(\Omega-3)$ has been associated with a decreased cardiovascular risk, thereby concentrating attention on a potentially preventive effect regarding tachyarrhythmias and sudden cardiac death. However, recent randomized controlled trials challenge the efficacy of the additional application of $\Omega-3$ and its anti-arrhythmic effect under certain clinical conditions. The present paper reflects the results of earlier and recent clinical studies with respect to the individual background conditions that may determine the clinical outcome of $\Omega-3$ supplementation and thereby explain apparently conflicting clinical results. It is concluded that the efficacy of $\Omega-3$ supplementation to prevent cardiac arrhythmias strongly depends on the underlying clinical and pharmacological conditions, a hypothesis that also is supported by data from experimental animal studies and by molecular interactions of $\Omega-3$ at the cellular level.
\end{abstract}

Keywords: omega-3 unsaturated fatty acids, arrhythmia, prevention, cardiovascular disease, myocardial infarction, death, sudden

\section{INTRODUCTION}

It is a great desire of humans to find golden ways to solve major problems, especially to treat severe diseases effectively in order to prolong life, whenever possible without creating additional risks or side effects. In the past, omega-3 polyunsaturated fatty acids $(\Omega$ 3), especially eicosapentaenoic acid (EPA) and docosahexaenoic acid (DHA), appeared to be compounds having the potential to fulfill this dream, if supplemented to daily nutrition in sufficient amounts.

Consequently, a huge amount of data has been accumulated on this topic and many reviews and meta-analyses have been published (Bucher et al., 2002; Leaf et al., 2003; Whelton et al., 2004; Yzebe and Lievre, 2004; Dhein et al., 2005; Hooper et al., 2006; Reiffel and McDonald, 2006; Wang et al., 2006; Lombardi and Terranova, 2007; Cheng and Santoni, 2008; Jenkins et al., 2008a; León et al., 2008; Siddiqui et al., 2008; Marik and Varon, 2009; Zhao et al., 2009; Filion et al., 2010; Mozaffarian et al., 2011a).

Based on this background the purpose of the present paper is not to again review all the available data on $\Omega$-3 effects or to discuss omega- 3 unsaturated fatty acids as essential compounds in human and animal biology. This paper focuses on the effects of supplementation with $\Omega-3$ on cardiac rhythm and discusses the potential clinical consequences of recent clinical studies that do not support the existence of this "golden $\Omega-3$ way". Furthermore, the complexity of the biological interactions of $\Omega-3$ as well as the variation of potential clinical settings are outlined in order to explain that supplementation with $\Omega-3$ does not necessarily result in an overall beneficial clinical effect in every condition.

\section{EARLIER CLINICAL STUDIES}

An inverse relationship between consumption of fish oil and cardiovascular risk was shown in early observational, case-control, and cohort studies, with respect to the occurrence of cardiovascular disease (Whelton et al., 2004), sudden cardiac death (SCD) and non-SCD from coronary heart disease (Daviglus et al., 1997), and with regard to SCD in apparently healthy persons (Siscovick et al., 1995; Albert et al., 1998, 2002; Hu et al., 2002; Mozaffarian et al., 2003). $\Omega$-3 levels in erythrocyte membranes were directly associated with a reduced rate of primary cardiac arrest (Siscovick et al., 1995). Similarly, elevated $\Omega-3$ blood levels were associated with a reduced risk of sudden death among men without evidence of prior cardiovascular disease (Albert et al., 2002).

These data were supported by prospective and randomized nutritional intervention studies of secondary prevention after acute myocardial infarction (AMI). In the Diet and Reinfarction Trial (DART) a diet rich in fish and cereals was associated with a significant $29 \%$ reduction of all-cause mortality within 2 years after AMI (Burr et al., 1989). In the Lyon Diet Heart Study the Mediterranean diet group [diet enriched by alpha-linolenic acid (ALA, $\Omega-3$ ) and olive oil, combined with an increased intake of 
cereals, fresh fruit, vegetables and fish, but limited intake of saturated fatty acids and linoleic acid $(\Omega-6)]$ had a significantly lower rate of the combined endpoint cardiac death and non fatal myocardial infarction, if compared to the control group taking a prudent western-type diet ( $p=0.0001$; follow-up 27 months; de Lorgeril et al., 1994, 1998, 1999).

A predefined supplementation with $\Omega-3$ was used in the large placebo-controlled, open labeled GISSI Prevenzione Trial (EPA + DHA $1 \mathrm{~g} /$ day, vitamin E $300 \mathrm{mg} /$ day, a combination of both, or placebo; GISSI-Prevenzione Investigators, 1999), focusing on secondary prevention after AMI. In this study the intervention arms using $\Omega-3$ showed a significant reduction of SCD - though this was not the primary endpoint of the GISSI Prevenzione Trial.

\section{ANIMAL STUDIES}

In parallel to these encouraging clinical data, animal studies (mostly using the rat or canine model) supported an antiarrhythmic effect of $\Omega-3$ especially with respect to ischemiainduced ventricular tachycardia (VT) or ventricular fibrillation (VF) (Matthan et al., 2005; Billman, 2006). The clearest effect in the prevention of VF by $\Omega-3$ could be shown in infusion studies using a special experimental canine model. In this model acute myocardial ischemia was induced at a site distant from a previous myocardial infarction during submaximal exercise thereby activating the autonomic nervous system (Billman, 2006) and inducing VF.

However, these clear effects of $\Omega-3$ under well-defined experimental conditions cannot simply be translated into the clinical situation, and several aspects have to be considered (Billman, 2006):

a. In this canine model not only superfusion with $\Omega$-3 but also the application of $\beta$-receptor antagonists, calcium-channel blockers, and endurance exercise training - all interventions that are routinely used in actual clinical practice - were effective in VF prevention.

b. Not all dogs were susceptible to ischemia-induced VF in this model. Animals resistant to VF were characterized by reduced $\beta$-receptor responsiveness and an intact parasympathetic regulation, indicating that these are first line mechanisms to prevent ischemia-induced tachyarrhythmias.

c. Finally, incorporation of $\Omega-3$ into the phospholipid bilayer can be expected to be significantly less in infusion studies as compared to feeding studies.

Feeding studies more closely may imitate the clinical situation, and under these conditions $\Omega-3$ can be expected to exert their effect primarily after being incorporated into the cellular membrane. Numerous animal feeding studies have been published between 1987 and 1999, and the results showed a considerable heterogeneity. Still, a meta-analysis of these studies suggests fish oil does prevent ischemia and ischemia-reperfusion induced VT/VF (Matthan et al., 2005).

Heterogeneity of experimental results also can be seen in more recent studies. In isolated hearts of pigs fed with fish oil for 8 weeks, spontaneous ischemia-induced sustained VT/VF was facilitated in the $\Omega-3$ group (Coronel et al., 2007). Other studies report increased resistance to ischemia-reperfusion injury after dietary $\Omega-3$ application, which also could be a basis to protect against reperfusion arrhythmias (Abdukeyum et al., 2008; Zeghichi-Hamri et al., 2010).

\section{RECENT CLINICAL STUDIES}

The results of the animal studies and their apparent inconsistencies may be remembered when judging the data of recent prospective, randomized, double-blind clinical studies that interrupted the long list of positive results of older studies investigating the effect of $\Omega-3$ on cardiovascular risk. In the following, these studies and the potential clinical consequences will be discussed in more detail.

1. Three randomized prospective studies evaluating the effect of high doses of $\Omega-3$ in patients with ICD-devices failed to give homogeneous results.

In one study recurrent VT events not due to myocardial ischemia were more common in patients treated with fish oil (1.3 $\mathrm{g} \Omega-3$ per day during a period of two years; $p<0.007$; Raitt et al., 2005).

However, in another study predominantly including patients with coronary artery disease, $\Omega$-3 supplementation was associated with a significant risk reduction for the primary endpoint (time to first ICD-event or death from any cause) by $31 \%$ $(p=0.033)$. The death rates did not significantly differ between the study groups. Remarkably in this study no significant effect of $\Omega-3$ could be shown in the subgroups of patients without coronary artery disease or with a left ventricular ejection fraction above 30\% (Leaf et al., 2005a).

Finally the SOFA-study did not show a significant effect of $\Omega-3$ supplementation on the primary endpoint (appropriate ICD-interventions for recurrent VT/VF or death from any cause; hazard ratio $0.86,95 \%$ CI $0.64-1.16$ ). The majority of the patients included in the SOFA-study had coronary artery disease, more than $60 \%$ with previous myocardial infarction; almost $40 \%$ of the study participants had various forms of cardiomyopathy or valvular heart disease (Brouwer et al., 2006).

In a meta-analysis of these three studies all-cause mortality did not significantly differ between the fish oil and the control groups (relative risk 0.70; 95\% CI 0.42-1.15; Jenkins et al., 2008b).

Finally, in a substudy of the GISSI-HF trial (566 heart failure patients with implanted ICD-devices, 57\% with previous myocardial infarction, mean follow-up 928 days) a statistically non-significant trend toward a lower risk of ICDdischarge in patients treated with $\Omega-3$ was shown [adjusted hazard ratio (HR) 0.80 ; 95\% CI 0.59-1.09; $p=0.152$ ]. However, mortality was similar in both groups [total mortality: $\Omega-3(26.6 \%)$, placebo (24.3\%); adjusted HR $1.25 ; 95 \% \mathrm{CI}$ $0.89-1.75 ; p=0.19$; mortality for arrhythmias: $\Omega-3(3.6 \%)$, placebo $(2.1 \%)$; adjusted HR $1.84 ; 95 \%$ CI 0.67-5.05; Finzi et al., 2011]. Therefore the clinical significance of these data remains debatable.

The apparent heterogeneity in the response of ICD-patients to fish oil supplementation could be a consequence of different study populations and different arrhythmic origins (ischemic versus non-ischemic). Heterogeneity also could be the result 
of different concomitant medications of the study populations including $\beta$-blockers, digoxin, amiodarone, and sotalol. A potential influence of medication on the effect of fish oil supplementation may be indicated by the results of the DART 2 study (Burr et al., 2003).

2. In the controlled prospective DART 2 trial conducted with general practitioners of South Wales male patients with stable angina ( $n=3,114$, under 70 years of age) were randomly allocated to four study groups with specific nutritional advises including the advise to eat oily fish or take fish oil capsules in two of the study groups. Survival was measured during a followup of 3-9 years. The risk of SCD was significantly increased in the group taking oily fish or fish oil capsules (HR 1.54; 95\% CI 1.06-2.23; Burr et al., 2003). The adverse effects of fish or fish oil capsules only occurred in men not taking beta-blockers or dihydropyridine calcium-channel blockers, and were increased in patients taking digoxin (Burr et al., 2005). Unfortunately, a conclusive interpretation of the DART 2 data is seriously limited as patient's recruitment and monitoring was interrupted for 1 year, long-term compliance was uncertain, and sudden death could not be ascertained in all cases (Burr et al., 2003).

3. In the large scale multicenter Japan EPA Lipid Intervention Study (JELIS; Yokoyama et al., 2007) consumption of $1.8 \mathrm{~g}$ EPA per day over a mean period of 4.6 years in hyperlipidemic patients (no AMI in the last 6 months, no serious heart disease) treated with statins resulted in a reduction of major cardiovascular events (combined endpoint including SCD, fatal and non-fatal myocardial infarction, and other non-fatal events including unstable angina, angioplasty, stenting, or coronary bypass grafting) from 3.5 to $2.8 \%$ ( $p=0.011$; HR $0.81 ; 95 \%$ CI 0.69-0.95). However, there was neither a reduction of SCD (0.2\% in both study arms; HR 1.06; 95\% CI 0.55-20.07) nor of coronary death $(0.3 \%$ in both study arms; HR $0.94 ; 95 \%$ CI 0.57-1.56) or all-cause death (control 2.8\%, EPA-group 3.1\%; HR 1.09; 95\% CI 0.92-1.28). Compared to the GISSI Prevenzione Trial death rates and especially the rates of SCD were very low in both groups and therefore may be difficult to be reduced further by any intervention (rates for SCD: JELIS $0.2 \%$ in both groups; GISSI 2.2\%/2.9\% $\Omega-3$ versus control; GISSIPrevenzione Investigators, 1999). Furthermore, these low event rates may at least in part be the result of a high fish consumption of the Japanese population at baseline. As most risk reduction already occurs at about $250 \mathrm{mg}$ EPA/DHA intake per day (Mozaffarian and Rimm, 2006), a further increase of $\Omega$-3 intake may not have a substantial additional effect on cardiac death reduction (Mozaffarian, 2007).

4. In the Alpha-Omega-Study, a multicenter, double-blind, placebo-controlled trial, 4,837 patients in the chronic stable phase after myocardial infarction (average 3.7 years after AMI) and $60-80$ years of age $(21.8 \%$ women $)$ were randomly assigned to one of four trial arms. Margarine was used in all trial arms, supplemented with either EPA/DHA (daily intake aimed to be $400 \mathrm{mg}$ ), alpha-linolenic acid (ALA, daily intake aimed to be $2 \mathrm{~g}$ ), EPA/DHA + ALA, or placebo, respectively (Kromhout et al., 2010). After a follow-up of 40 months, $13.9 \%$ of the patients had a major cardiovascular event (death, non-fatal cardiovascular events, or cardiac intervention). The rates of the primary endpoint did not differ between the study groups. In addition, in all secondary endpoints, including ventriculararrhythmia and total death, there was no significant difference between the study groups. Importantly, a high percentage of the patients received "state of the art medication," including statins.

In a post hoc analysis after unblinding of the data in the subgroup of patients with diabetes ventricular-arrhythmia-related events tended to be reduced in the EPA/DHA group (HR 0.51; 95\% CI 0.24-1.11) and significantly were reduced in the ALA group (HR 0.39; 95\% CI 0.17-0.88). In a secondary analysis of the Alpha-Omega Trial taking high risk patients with previous myocardial infarction and diabetes the EPA/DHA + ALA group experienced significantly less ventricular-arrhythmiarelated events (HR 0.16; 95\% CI 0.04-0.69; Kromhout et al., 2011). These differential results support the necessity to exactly define the clinical conditions under which supplementation of $\Omega-3$ may be beneficial.

5. In the OMEGA trial the effect of supplementation with $1 \mathrm{~g}$ /day of esterified EPA/DHA on the rate of SCD and other clinical events within 1 year after AMI was tested in 3,851 patients (25.6\% female, mean age 64.0 years; Rauch et al., 2006, 2010). A 1-year follow-up was chosen, as the risk of cardiac death after AMI including a presumed arrhythmic death is highest in the first 3 months after the event (Solomon et al., 2005; Pouleur et al., 2010). Furthermore, in the GISSI trial, the significance in lowering SCD by $\Omega-3$ had already been reached within 120 days (Marchioli et al., 2002). Following guidelines for the management of AMI and secondary prevention $77 \%$ of the patients in the OMEGA trial received acute percutaneous coronary intervention, and/or thrombolysis (8.3\%). At hospital discharge the following medications were prescribed for almost all patients: beta-blockers (94\%), ACE-inhibitors (83\%), ARBs $(8 \%)$, statins (94\%), acetylsalicylic acid (95\%), and clopidogrel (88\%). Under these conditions, the rates of SCD were $1.5 \%$ in both study groups (OR $0.95 ; 95 \%$ CI $0.56-1.60$ ) and total mortality was $4.6 \%$ in the $\Omega-3$ group and $3.7 \%$ in the control group (OR 1.25; 95\% CI 0.90-1.72). In none of the predefined secondary endpoints, including total death, major adverse cardiovascular and cerebrovascular events, and revascularization procedures in survivors, was found a significant difference between the study groups, and not even a trend in favor of the $\Omega-3$ group could be observed. In addition, ICD-terminated VT or VF in survivors was $0.1 \%(n=2 / 1,654)$ in the control group but $0.5 \%(n=9 / 1,705)$ in the $\Omega-3$ group $[p=0.06$; OR $(95 \%$ CI): 4.47 (0.97-20.74)]. Furthermore, there was no significant difference between the study groups with regard to SCD or total death in any of the predefined subgroups of patients with higher risk (diabetes, age $>70$ years, no acute revascularization, ejection fraction $<35 \%$ ).

Despite these apparently homogeneous results their interpretation is limited as the case estimate in the OMEGA-study was based on an overestimation of the rate of SCD in the control group, thereby leading to an underpowering of the study.

6. Two other randomized controlled trials published recently also failed to show a clear beneficial effect of $\Omega-3$ supplementation. In 563 elderly Norwegian men at high cardiovascular risk a non-significant tendency to a reduced all-cause mortality 
could be observed (HR $0.53 ; 95 \%$ CI $0.27-1.04$ ), but the rate of cardiovascular events remained unchanged (HR 0.89; 95\% CI 0.55-1.45, follow-up 3 years; Einvik et al., 2010).

In 2,501 patients with a history of myocardial infarction, unstable angina or ischemic stroke supplementation with EPA/DHA was not associated with a significant decrease of major vascular events during a follow-up of 4.7 years (HR 1.08; 95\% CI 0.79-1.47; Galan et al., 2010).

Which conclusions may be drawn from the clinical studies and the animal studies discussed above?

a. The effect of $\Omega-3$ supplementation may depend on the background diet and the pre-existent intake of fish oil (Mozaffarian and Rimm, 2006; Reiffel and McDonald, 2006; Mozaffarian, 2007).

b. With regard to earlier studies, treatment of patients with coronary artery disease, especially treatment of patients with myocardial infarction has improved markedly. In the GISSI trial (inclusion period October 1993 to September 1995) only $4.4 \%$ of the patients had acute coronary revascularization at baseline, and only $4.7 \%$ were on cholesterol-lowering drugs at hospital discharge, increasing to only $46 \%$ after 42 months of follow-up (GISSI-Prevenzione Investigators, 1999). Furthermore, only $43.9 \%$ of the patients included in the GISSI trial were on beta-blocker treatment at the start of the study, and this percentage decreased during followup. It therefore may be speculated that up-to-date guideline adjusted treatment of AMI (including acute revascularization, medical treatment, and support of life style changes) may interfere with molecular and cellular $\Omega-3$ interactions thereby weakening or competing with a potential beneficial $\Omega-3$ effect. Although the available data not homogeneously support this hypothesis (Marchioli et al., 2007), this aspect should strongly be considered in future research.

c. The anti-arrhythmic effect of $\Omega-3$ may depend on the pathophysiological conditions that facilitate arrhythmias. The clinical and experimental data outlined above suggest that $\Omega-3$ supplementation may especially protect against ischemia-induced arrhythmias. Therefore, prevention of ischemia by modern treatments (i.e., revascularization, beta-blockers, statins, ACE-inhibitors, inhibition of thrombocyte aggregation, physical exercise) could attenuate a potentially beneficial effect of $\Omega-3$. Beta-blockers are well known to prevent sudden death, and even statins could have some anti-arrhythmic effects (Anh and Marine, 2004; Lorenz et al., 2005).

d. Potential anti-arrhythmic effects of $\Omega-3$ by augmentation of vagal activity (Mozaffarian et al., 2005; O'Keefe et al., 2006) may be blunted by beta-blocker treatment and increased physical training during cardiac rehabilitation (Nolan et al., 2008; Billman, 2009).

In summary, the anti-arrhythmic effect proven under experimental conditions in animal models and suggested in the earlier clinical studies appears to depend on the clinical conditions being studied. These clinical conditions are determined by the type and stage of the underlying myocardial disease and represent a sum of various pathophysiological conditions (including ischemia, reperfusion, ischemic preconditioning, scar tissue, inflammation, congenital defects, etc.) and the effects of modern medication including beta-blockers, ACE-inhibitors, statins, and other interventions potentially interfering with the arrhythmic risk, such as exercise training.

These considerations may also apply to the role of $\Omega-3$ in the prevention of atrial fibrillation. Positive results (Mozaffarian et al., 2004, primary prevention in patients > 65 years of age; Calò et al., 2005, patients undergoing coronary artery surgery; Macchia et al., 2008, postmyocardial infarction patients) were not confirmed in more recent studies and meta-analyses (Kowey et al., 2010; Saravanan et al., 2010; Bianconi et al., 2011; Farquharson et al., 2011; Liu et al., 2011). Still, it was demonstrated recently, that the use of fish oil (DHA $1.5 \mathrm{~g}$ and EPA $0.3 \mathrm{~g}$ daily) resulted in a prolongation and reduced dispersion of pulmonary venous and left atrial effective refractory periods in patients with paroxysmal atrial fibrillation (Kumar et al., 2011). Furthermore, in patients with persistent atrial fibrillation on amiodarone and a reninangiotensin-aldosterone system inhibitor, taking $\Omega-3$ ( $2 \mathrm{~g} /$ day) improved the probability of maintaining sinus rhythm after direct current cardioversion (Nodari et al., 2011). Similar to the prevention of ventricular tachyarrhythmias, prevention of atrial fibrillation therefore may depend on distinct clinical and pathophysiological conditions and concomitant medication. The ongoing OPERA-trial, including a total of 1,516 patients scheduled for cardiac surgery and in sinus rhythm, will give more insight into the potential role of $\Omega-3$ supplementation to prevent post-operative atrial fibrillation (Mozaffarian et al., 2011b).

\section{SOME ASPECTS OF THE MOLECULAR AND CELLULAR INTERACTIONS OF $\Omega$-3 TO EXPLAIN HETEROGENEOUS CLINICAL RESULTS}

For understanding the seemingly heterogeneous efficacy of $\Omega-3$ supplementation in preventing tachyarrhythmias, it is important to reflect on their molecular and cellular interactions as has been delineated extensively in recent reviews (Leaf et al., 2003, 2005b; Dhein et al., 2005; McLennan and Abeywardena, 2005; Den Ruijter et al., 2007; Lombardi and Terranova, 2007; Siddiqui et al., 2008). In the following, only some aspects of potential relevance for interpretation of the clinical data are discussed:

There are three major ways in which $\Omega-3$ may interfere with cellular and membrane function, thereby potentially moderating cardiac rhythm:

a. Direct interactions of $\Omega-3$ with membrane bound proteins like the fast sodium channel, the voltage-gated L-type $\mathrm{Ca}^{2+}$ channel, specific potassium channels, and the $\mathrm{Na}^{+} / \mathrm{Ca}^{++}$-exchanger (Hallaq et al., 1990, 1992; Honore et al., 1994; Xiao et al., 1995, 1997; Kang and Leaf, 1996; Leifert et al., 1999; Leaf et al., 2003; Den Ruijter et al., 2007; Wang et al., 2010). Such interactions may occur predominantly with circulating $\Omega-3$ when it is delivered by acute administration and infusion.

b. Incorporation into the phospholipid bilayer, thereby potentially changing membrane fluidity, and/or forming $\Omega-3$ rich microdomains, and/or interacting with internal binding sites. This may result in a change of the function of membrane bound proteins like ion channels, receptors and signal transduction 
systems (McMurchie et al., 1988; Croset and Kinsella, 1989; Kinoshita et al., 1994; Grynberg et al., 1996; Leifert et al., 1999, 2000b; McLennan, 2001; Den Ruijter et al., 2007). Incorporation into the cellular membranes predominantly is achieved by dietary long-term administration of $\Omega-3$.

c. Interaction with intracellular pathways including gene expression and metabolism of phosphoinositides (Judé et al., 2006).

Circulating $\Omega-3$ compounds are likely to have different electrophysiological effects, compared to $\Omega-3$ incorporated into the membranes (Den Ruijter et al., 2007 for review). For example, peak cardiac sodium current was reduced by $51 \%$ after acute administration of EPA and DHA in neonatal rat cardiomyocytes (Xiao et al., 1995), but remained unaffected by $\Omega-3$ incorporated in pig and rat cardiomyocytes (Leifert et al., 2000a; Verkerk et al., 2006). Differential effects of circulating versus incorporated $\Omega-3$ have also been demonstrated with respect to various potassium channels and the regulation of calcium homeostasis (Den Ruijter et al., 2007 for review). Incorporated $\Omega-3$, however, also may prevent further action potential (AP) shortening induced by circulating $\Omega$-3. Patients with high levels of incorporated $\Omega$-3 therefore may not have a further benefit from short term $\Omega-3$ supplementation (Den Ruijter et al., 2010). This could be of a direct clinical relevance, as acute $\Omega-3$ supplementation may be used for prevention of atrial fibrillation induced by cardiac surgery, which is being investigated in the OPERA-trial (Mozaffarian et al., 2011b).

Apart from these considerations the molecular interactions of $\Omega-3$ and their effects on cardiac rhythm may be influenced by a large variety of additional conditions:

a. The various kinds of $\Omega-3$ formulations being used (re-esterified triacylglycerides, ethyl-esters or phospholipids; Neubronner et al., 2011; Schuchardt et al., 2011).

b. The activity state of membrane bound proteins and ligand occupation of specific receptors involved in signal transduction (Rauch et al., 1989; Xiao et al., 1998; Den Ruijter et al., 2007), or the increased responsiveness of inhibitory G-proteins after ischemic preconditioning (Niroomand et al., 1995).

c. The activity of cellular phospholipases and the presence of lysophosphatides that change phospholipid environment and function of membrane bound proteins (Chien et al., 1981; Corr et al., 1984; Rauch et al., 1994), and may even vary between different myocardial regions depending on the degree of ischemia and/or inflammation.

d. The heterogeneity of electrical stability of myocardial cells in the diseased heart muscle due to regional differences with regard to various degrees of ischemia and tissue damage, ischemic preconditioning, etc. (Dhein et al., 2005). In this respect it should also be remembered, that in patients with coronary artery disease, myocardium is not presenting as a homogeneous and healthy tissue experiencing acute ischemia in a well-defined area, but rather as a mixture of healthy myocardium, hypertrophied tissue, scar tissue, and ischemic myocardium and includes areas of tissue with ischemic preconditioning, inflammation, various degrees of membrane phospholipid degradation and with more or less acute or chronic stretch, etc. (Janse et al., 2003).

e. The species (human, various animals) being studied. The characteristics of APs vary significantly between human and various animal myocardial cells and with gender (Karagueuzian et al., 1982; Shattock and Bers, 1989; Cheng, 2006; Tanaka et al., 2008).

f. The various mechanisms that trigger VT and VF. Under clinical conditions VT or VF are predominantly caused by triggered activity or by re-entry mechanisms. Fish oil shortens cardiac AP and accentuates the AP notch, which may lead to depression or even loss of the AP dome (Verkerk et al., 2006, 2007). Under clinical conditions where the AP is prolonged triggered activity may be the predominant pro-arrhythmic mechanism, which could be inhibited in isolated cardiomyocytes from rabbits and from patients with end stage heart failure by superfusion with $\Omega-3$ (Den Ruijter et al., 2008). Triggered activity also could be inhibited in pig cardiomyocytes (Den Ruijter et al., 2006). In keeping with these experimental results $\Omega$-3 were effective in reducing the arrhythmic risk in patients with idiopathic dilated cardiomyopathy (Nodari et al., 2009).

Conversely, AP shortening also may be pro-arrhythmic by reducing the refractory period and thereby promoting re-entry. Supplementation with $\Omega-3$ may increase a preexisting heterogeneity in AP duration and repolarization (Verkerk et al., 2007), as can be seen, for example, in acute ischemia (Yan et al., 2004). In this way the occurrence of unidirectional block and re-entry may be facilitated (Janse and Wit, 1989). In the clinical situation therefore supplementation with $\Omega-3$ may prevent or facilitate ventricular tachyarrhythmias depending on the predominant underlying arrhythmic mechanism (Den Ruijter et al., 2007).

Based on these considerations it becomes apparent that $\Omega$ 3 do not have a specific way to act, but rather possess multiple sites of potential actions, that may be influenced by a number of external conditions at the cellular and molecular level. Multiple sites of interaction between $\Omega-3$ and myocardial tissue in combination with various possible ways of interference with these biochemical interactions are unlikely to result in an unequivocally predictable and homogeneous beneficial effect on clinical outcomes.

\section{CONCLUDING REMARKS}

$\Omega$-3 clearly interfere with the physiology of myocardial cell membranes through a variety of specific and unspecific pathways, and thereby exhibit anti-arrhythmic effects under certain well-defined experimental and clinical conditions. However, these membrane effects of $\Omega-3$ are complex. This complexity makes it difficult to predict the effects of $\Omega-3$ supplementation on cardiac rhythm within the wide variety of conditions that represent clinical practice. For the future it will be necessary to define exactly the clinical conditions in which supplementation with of $\Omega-3$ is beneficial, and without potentially harmful effects.

\section{ACKNOWLEDGMENTS}

We are grateful to Dr Margaret Cupples, Queen's University, Belfast, for her thorough revision of this paper in its presentation and language. 


\section{REFERENCES}

Abdukeyum, G. G., Owen, A. J., and McLennan, P. L. (2008). Dietary (n-3) long-chain polyunsaturated fatty acids inhibit ischemia and reperfusion arrhythmias and infarction in rat heart not enhanced by ischemic preconditioning. J. Nutr. 138, 1902-1909.

Albert, C. M., Campos, H., Stampfer, M. J., Ridker, P. M., Manson, J. E., Willett, W. C., and Ma, J. (2002). Blood levels of long-chain n-3 fatty acids and the risk of sudden death. N. Engl. J. Med. 346, 1113-1118.

Albert, C. M., Hennekens, C. H., O’Donnell, C. J., Ajani, U. A., Carey, V. J., Willett, W. C., Ruskin, J. M., and Manson, J. E. (1998). Fish consumption and risk of sudden cardiac death. JAMA 279, 23-28.

Anh, D., and Marine, J. E. (2004). Beta blockers as anti-arrhythmic agents. Heart Fail. Rev. 9, 139-147.

Bianconi, L., Calò, L., Mennuni, M., Santini, L., Morosetti, P., Azzolini, P., Barbato, G., Biscione, F., Romano, P., and Santini, M. (2011). n-3 polyunsaturated fatty acids for the prevention of arrhythmia recurrence after electrical cardioversion of chronic persistent atrial fibrillation: a randomized, double-blind, multicentre study. Europace 13, 174-181.

Billman, G. E. (2006). A comprehensive review and analysis of 25 years of data from an in vivo canine model of sudden cardiac death: implications for future anti-arrhythmic drug development. Pharmacol. Ther. 111, 808-835.

Billman, G. E. (2009). Cardiac autonomic neural remodelling and susceptibility to sudden cardiac death: effect of endurance exercise training. Am. J. Physiol. Heart Circ. Physiol. 297, H1171-H1193.

Brouwer, I. A., Zock, P. L., Camm, A. J., Böcker, D., Hauer, R. N. W., Wever, E. F. D., Dullemeijer, C., Ronden, J. E., Katan, M. B., Lubinski, A., Buschler, H., Schouten, E. G., for the SOFA Study Group. (2006). Effect of fish oil on ventricular tachyarrhythmia and death in patients with implantable cardioverter defibrillators: the Study on Omega-3 Fatty Acids and Ventricular Arrhythmia (SOFA) randomized trial. JAMA 295, 2613-2619.

Bucher, H. C., Hengstler, P., Schindler, C., and Meier, G. (2002). N-3 polyunsaturated fatty acids in coronary heart disease: a meta-analysis of randomized controlled trials. Am. J. Med. 112, 298-304.

Burr, M. L., Ashfield-Watt, P. A. L., Dunstan, F. D. J., Fehily, A. M., Breay, P.,
Ashton, T., Zotos, P. C., Haboubi, N. A. A., and Elwood, P. C. (2003). Lack of benefit of dietary advice to men with angina: results of a controlled trial. Eur. J. Clin. Nutr. 57, 193-200.

Burr, M. L., Dunstan, F. D. J., and George, C. H. (2005). Is fish oil good or bad for heart disease? Two trials with apparently conflicting results. $J$. Membr. Biol. 206, 155-163.

Burr, M. L., Fehily, A. M., Gilbert, J. F., Rogers, S., Holliday, R. M., Sweetnam, P. M., Elwood, P. C., and Deadman, N. M. (1989). Effects of changes in fat, fish, and fibre intakes on death and myocardial reinfarction: Diet and Reinfarction Trial (DART). Lancet 334, 757-761.

Calò, L., Bianconi, L., Colivicchi, F., Lamberti, F., Loricchio, M. L., de Ruvo, E., Meo, A., Pandozi, C., Staibano, M., and Santini, M. (2005). N-3 fatty acids for the prevention of atrial fibrillation after coronary artery bypass surgery: a randomized, controlled trial. J. Am. Coll. Cardiol. 45, 1723-1728.

Cheng, J. (2006). Evidences of the gender-related differences in cardiac repolarization and the underlying mechanisms in different animal species and human. Fundam. Clin. Pharmacol. 20, 1-8.

Cheng, J. W., and Santoni, F. (2008). Omega-3 fatty acid: a role in the management of cardiac arrhythmias? J. Altern. Complement. Med. 14, 965-974.

Chien, K. R., Reeves, J. P., Buja, L. M., Bonte, F., Parkey, R. W., and Willerson, J. T. (1981). Phospholipid alterations in canine ischemic myocardium. Temporal and topographical correlations with Tc99m-PPi accumulation and an in vitro sarcolemmal $\mathrm{Ca}^{2+}$ permeability defect. Circ. Res. 48, 711-719.

Coronel, R., Wilms-Schopman, F. J. G., Den Ruijter, H. M., Belterman, C. N., Schumacher, C. A., Opthof, T., Hovenier, R., Lemmens, A. G., Terpstra, A. H. M., Katan, M. B., and Zock, P. (2007). Dietary n-3 fatty acids promote arrhythmias during acute regional myocardial ischemia in isolated pig hearts. Cardiovasc. Res. 73, 386-394.

Corr, P. B., Gross, R. W., and Sobel, B. E. (1984). Amphipathic metabolites and membrane dysfunction in ischemic myocardium. Circ. Res. 55, 135-154.

Croset, M., and Kinsella, J. E. (1989). Changes in phospholipid fatty acid composition of mouse cardiac organelles after feeding graded amounts of docosahexaenoate in presence of high levels of linoleate.
Effect on cardiac ATPase activities. Ann. Nutr. Metab. 33, 125-191.

Daviglus, M. L., Stamler, J., Orencia, A. J., Dyer, A. R., Liu, K., Greenland, P., Walsh, M. K., Morris, D., and Shekelle, R. B. (1997). Fish consumption and the 30-year risk of fatal myocardial infarction. N. Engl. J. Med. 336, 1046-1053.

de Lorgeril, M., Renaud, S., Mamelle, N., Salen, P., Martin, J. L., Monjaud, I., Guidollet, J., Touboul, P., and Delaye, J. (1994). Mediterranean alpha-linolenic acid-rich diet in secondary prevention of coronary heart disease. Lancet 343, 1454.

de Lorgeril, M., Salen, P., Martin, J. L., Monjaud, I., Boucher, P., and Mamelle, N. (1998). Mediterranean dietary pattern in a randomized trial. Arch. Intern. Med. 158, 1181-1187.

de Lorgeril, M., Salen, P., Martin, J. L., Monjaud, I., Delaye, J., and Mamelle, N. (1999). Mediterranean diet, traditional risk factors, and the rate of cardiovascular complications after myocardial infarction: final report of the Lyon Diet Heart Study. Circulation 99, 779-785.

Den Ruijter, H. M., Berecki, G., Opthof, T., Verkerk, A. O., Zock, P. L., and Coronel, R. (2007). Pro- and antiarrhythmic properties of a diet rich fish oil. Cardiovasc. Res. 73, 316-325.

Den Ruijter, H. M., Berecki, G., Verkerk, A. O., Bakker, D., Baartscheer, A., Schumacher, C. A., Belterman, C. N. W., de Jonge, N., Fiolet, J. W. T., Brouwer, I. A., and Coronel, R. (2008). Acute administration of fish pills inhibits triggered activity in isolated myocytes from rabbits and patients with heart failure. Circulation 117, 536-544.

Den Ruijter, H. M., Verkerk, A. O., Berecki, G., Bakker, D., van Ginneken, A. C. G., and Coronel, R. (2006). Dietary fish oil reduces the occurrence of early afterdepolarizations in pig ventricular myocytes. $J$. Mol. Cell. Cardiol. 41, 914-917.

Den Ruijter, H. M., Verkerk, A. O., and Coronel, R. (2010). Incorporated fish oil fatty acids prevent action potential shortening induced by circulating fish oil fatty acids. Front. Physiol. 1, 149. doi:10.3389/fphys.2010.00149

Dhein, S., Michaelis, B., and Mohr, F. W. (2005). Antiarrhythmic and electrophysiological effects of long-chain w-3 polyunsaturated fatty acids. Naunyn Schmiedebergs Arch. Pharmacol. 371, 202-211.

Einvik, G., Klemsdal, T. O., Sandvik, L., and Hjerkinn, E. M. (2010). A randomized clinical trial on $n-3$ polyunsaturated fatty acids supplementation and all-cause mortality in elderly men at high cardiovascular risk. Eur. J. Cardiovasc. Prev. Rehabil. 17, 588-592.

Farquharson, A. L., Metcalf, R. G., Sanders, P., Stuklis, R., Edwards, J. R., Gibson, R. A., Cleland, L. G., Sullivan, T. R., James, M. J., and Young, G. D. (2011). Effect of dietary fish oil on atrial fibrillation after cardiac surgery. Am. J. Cardiol. 108, 851-856.

Filion, K. B., El Khoury, F., Bielinski, M., Schiller, I., Dendukuri, N., and Brophy, J. M. (2010). Omega3 fatty acids in high-risk cardiovascular patients: a meta-analysis of randomized controlled trials. BMC Cardiovasc. Disord. 10, 24. doi:10.1186/1471-2261-10-24

Finzi, A. A., Latini, R., Barlera, S., Rossi, M. G., Ruggeri, A., Mezzani, A., Favero, C., Franzosi, M. G., Serra, D., Lucci, D., Bianchini, F., Bernasconi, R., Maggioni, A. P., Nicolosi, G., Porcu, M., Tognoni, G., Tavazzi, L., and Marchiolo, R. (2011). Effects of $\mathrm{n}-3$ polyunsaturated fatty acids on malignant ventricular arrhythmias in patients with chronic heart failure and implantable cardioverterdefibrillators: a substudy of the Gruppo Italiano per lo Studio della Sopravvivenza nell'Insufficienza Cardiaca (GISSI-HF) trial. Am. Heart J. 161, 338-343.

Galan, P., Kesse-Guyot, E., Czernichow, S., Briancon, S., Blacher, J., Hercberg, S., for the SU.FOL.OM3 Collaborative Group. (2010). Effects of B vitamins and omega 3 fatty acids on cardiovascular diseases: a randomised placebo controlled trial. BMJ 341, c6273

GISSI-Prevenzione Investigators (Gruppo Italiano per lo Studio della Sopravvivenza nell ' Infarto miocardico). (1999). Dietary supplementation with n-3 polyunsaturated fatty acids and vitamin $\mathrm{E}$ after myocardial infarction: results of the GISSI-Prevenzione trial. Lancet 354, 447-455.

Grynberg, A., Fournier, A., Sergiel, J. P., and Athias, P. (1996). Membrane docosahexaenoic acid vs. eicosapentaenoic acid and the beating function of the cardiomyocyte and its regulation through the adrenergic receptors. Lipids 31, S205-S210.

Hallaq, H., Sellmayer, A., Smith, T. W., and Leaf, A. (1990). Protective effect of eicosapentaenoic acid on ouabain toxicity in neonatal rat cardiac myocytes. Proc. Natl. Acad. Sci. U.S.A. 87, 7834-7838.

Hallaq, H., Smith, T. W., and Leaf, A. (1992). Modulation of 
dihydropyridine-sensitive calcium channels in heart single cells by fish oil fatty acids. Proc. Natl. Acad. Sci. U.S.A. 89, 1760-1764.

Honore, E., Barhanin, J., Attali, B., Lesage, F., and Lazdunski, M. (1994). External blockade of the major cardiac delayed-rectifier $\mathrm{K}+$ channel (Kv1.5) by polyunsaturated fatty acids. Proc. Natl. Acad. Sci. U.S.A. 91, 1937-1941.

Hooper, L., Thompson, R. L., Harrison, R. A., Summerbell, C. D., Ness, A. R., Moore, H. J., Worthington, H. V., Durrington, P. N., Higgins, J. P., Capps, N. E., Riemersma, R. A., Ebrahim, S. B., and Davey Smith, G. (2006). Risks and benefits of omega 3 fats for mortality, cardiovascular disease, and cancer: systematic review. BMJ 332, 752-760.

Hu, F. B., Bronner, L., Wilett, W. C., Stampfer, M. J., Rexrode, K. M., Albert, C. M., Hunter, D., and Manson, J. E. (2002). Fish and omega-3 fatty acid intake and risk of coronary heart disease in woman. JAMA 287, 1815-1821.

Janse, M. J., Coronel, R., WiilmsSchopman, F. J., and de Groot, J. R. (2003). Mechanical effects on arrhythmogenesis: from pipette to patient. Prog. Biophys. Mol. Biol. 82, 187-195.

Janse, M. J., and Wit, A. L. (1989). Electrophysiological mechanisms of ventricular arrhythmias resulting from myocardial ischemia and infarction. Physiol. Rev. 69, 1049-1169.

Jenkins, D. J. A., Josse, A. R., Dorian, P., Burr, M. L., LaBelle Trangmar, R., Kendall, C. W. C., and Cunnane, S. C. (2008a). Heterogeneity in randomized controlled trials of long chain (Fish) omega-3 fatty acids in restenosis, secondary prevention and ventricular arrhythmias. J. Am. Coll. Nutr. 27, 367-378.

Jenkins, D. J. A., Josse, A. R., Beyene, J., Dorian, P., Burr, M. L., LaBelle, R., Kendall, C. W. C., and Cunnane, S. C. (2008b). Fish-oil supplementation in patients with implantable cardioverter defibrillators: a meta-analysis. CMAJ 178, 157-164.

Judé, S., Roger, S., Martel, E., Besson, P., Richard, S., Bougnoux, P., Champeroux, P., and Le Guennec, J. Y. (2006). Dietary long-chain omega-3 fatty acids of marine origin: a comparison of their protective effects on coronary heart disease and breast cancers. Prog. Biophys. Mol. Biol. 90, 299-325.

Kang, J. X., and Leaf, A. (1996). Evidence that free polyunsaturated fatty acids modify $\mathrm{Na}+$ channels by directly binding to the channel proteins. Proc. Natl. Acad. Sci. U.S.A. 93, 3542-3546.

Karagueuzian, H. S., Pennec, J. P., Deroubbaix, E., de Leiris, J., and Coraboeuf, E. (1982). Effects of excess free fatty acids on the electrophysiological properties of ventricular specialized conducting tissue: a comparative study between the sheep and the dog. J. Cardiovasc. Pharmacol. 4, 462-468.

Kinoshita, I., Itoh, K., Nishida-Nakai, M., Hirota, H., Otsuji, S., and Shibata, N. (1994). Antiarrhythmic effects of eicosapentaenoic acid during myocardial infarction-enhanced cardiac microsomal $(\mathrm{Ca}(2+)$ $\mathrm{Mg}(2+)$-ATPase activity. Jpn. Circ. J. 58, 903-912.

Kowey, P. R., Reiffel, J. A., Ellenbogen, K. A., Naccarelli, G. V., and Pratt, C. M. (2010). Efficacy and safety of prescription omega- 3 fatty acids fort he prevention of recurrent symptomatic atrial fibrillation: a randomized controlled trial. JAMA 304, 2363-2372.

Kromhout, D., Geleijnse, J. M., de Goede, J., Oude Griep, L. M., Mulder, B. J., de Boer, M. J., Deckers, J. W., Boersma, E., Zock, P. L., and Giltay, E. J. (2011). N-3 fatty acids, ventricular arrhythmiarelated events, and fatal myocardial infarction in postmyocardial infarction patients with diabetes. Diabetes Care 34, 2515-2520.

Kromhout, D., Giltay, E. J., Geleijnse, J. M., for the Alpha Omega Trial Group. (2010). N-3 fatty acids and cardiovascular events after myocardial infarction. N. Engl. J. Med. 363, 2015-2026.

Kumar, S., Sutherland, F., Teh, A. W., Heck, P. M., Lee, G., Garg, M. L., and Sparks, P. B. (2011). Effects of chronic omega-3 polyunsaturated fatty acid supplementation on human pulmonary vein and left atrial electrophysiology in paroxysmal atrial fibrillation. Am. J. Cardiol. 108, 531-535.

Leaf, A., Albert, C. M., Josephson, M., Steinhaus, D., Kluger, J., Kang, J. X., Cox, B., Zhang, H., Schoenfeld, D., for the Fatty Acid Antiarrhythmia Trial Investigators. (2005a). Prevention of fatal arrhythmias in high-risk subjects by fish oil n-3 fatty acid intake. Circulation 112, 2762-2768.

Leaf, A., Xiao, Y. F., Kang, J. X., and Billman, G. E. (2005b). Membrane effects of the n-3 fish oil fatty acids, which prevent fatal ventricular arrhythmias. J. Membr. Biol. 206, 129-139.
Leaf, A., Kang, J. X., Xiao, Y. F., and Billman, G. E. (2003). Clinical prevention of sudden cardiac death by $n-3$ polyunsaturated fatty acids and mechanism of prevention of arrhythmias by n-3 fish oils. Circulation 107, 2646-2652.

Leifert, W. R., Jahangiri, A., Saint, D. A., and McMurchie, E. J. (2000a). Effects of dietary n-3 fatty acids on contractility. $\mathrm{Na}+$ and $\mathrm{K}+$ currents in a rat cardiomyocyte model of arrhythmia. J. Nutr. Biochem. 11, 282-292.

Leifert, W. R., Jahangiri, A., and McMurchie, E. J. (2000b). Membrane fluidity changes are associated with antiarrhythmic effects of docosahexaenoic acid in adult rat cardiomyocytes. J. Nutr. Biochem. $11,38-44$.

Leifert, W. R., McMurchie, E. J., and Saint, D. A. (1999). Inhibition of cardiac sodium currents in adult rat myocytes by $n-3$ polyunsaturated fatty acids. J. Physiol. 283, H1688H1694.

León, H., Shibata, M. C., Sivakumaran, S., Dorgan, M., Chatterley, T., and Tsuyuki, R. T. (2008). Effect of fish oil on arrhythmias and mortality: systematic review. BMJ 337, a2931.

Liu, T., Korantzopoulos, P., Shehata, M., Li, G., Wang, X., and Kaul, S. (2011). Prevention of atrial fibrillation with omega-3 fatty acids: a meta-analysis of randomized clinical trials. Heart 97, 1034-1040.

Lombardi, F., and Terranova, P. (2007). Anti-arrhythmic properties of $\mathrm{n}$ 3 poly-unsaturated fatty acids ( $n$ 3 PUFA). Curr. Med. Chem. 14, 2070-2080.

Lorenz, H., Jünger, C., Seidl, K., Gitt, A., Schneider, S., Schiele, R., Wienbergen, H., Winkler, R., Gottwik, M. Delius, W., Senges, J., and Rauch, B. (2005). Do statins influence the prognostic impact of non-sustained ventricular tachycardia after STelevation myocardial infarction? Eur. Heart J. 26, 1078-1085.

Macchia, A., Monte, S., Pellegrini, F., Romero, M., Ferrante, D., Doval, H., D'Ettore, A., Maggioni, A. P., and Tognoni, G. (2008). Omega-3 fatty acid supplementation reduces one-year risk of atrial fibrillation in patients hospitalized with myocardial infarction. Eur. J. Clin. Pharmacol. 64, 627-634.

Marchioli, R., Barzi, F., Bomba, E., Chieffo, C., Gregorio, D. D., Mascio, R. D., Franzosi, M. G., Geraci, E., Levantensi, G., Maggioni, A. P., Mantini, L., Marfisi, R. M., Mastroguiseppe, G., Mininni, N., Nicolosi, G. L., Santini, M., Schweiger, C., Tavazzi,
L., Tognoni, G., Tucci, C., Valugassa, F., on behalf of the GISSIPrevenzione Investigators. (2002). Early protection against sudden death by $n-3$ polyunsaturated fatty acids after myocardial infarction. Time-course analysis of the results of the Gruppo Italiano per lo Studio della Sopravvivenza nell'Infarto Miocardio (GISSI) - Prevenzione. Circulation 105, 1897-1903.

Marchioli, R., Marfisi, R. M., Borreli, G., Chieffo, C., Franzosi, M. G., Levantesi, G., Maggioni, A. P., Nicolosi, G. L., Scarano, M., Silletta, M. G., Schweiger, C., Tavazzi, L., and Tognoni, G. (2007). Efficacy of $n-3$ polyunsaturated fatty acids according to clinical characteristics of patients with recent myocardial infarction: insight from the GISSI-Prevenzione Trial. J. Cardiovasc. Med. 8(Suppl. 1), S34-S37.

Marik, P. E., and Varon, J. (2009). Omega-3 dietary supplements and the risk of cardiovascular events: a systematic review. Clin. Cardiol. 32, 365-372.

Matthan, N. R., Jordan, H., Chung, M., Lichtenstein, A. H., Lathrop, D. A., and Lau, J. (2005). A systematic review and meta-analysis of the impact of $\omega-3$ fatty acids on selected arrhythmia outcomes in animal models. Metabolism 54, 1557-1565.

McLennan, P. L. (2001). Myocardial membrane fatty acids and the antiarrhythmic actions of dietary fish oil in animal models. Lipids 36, S111S114.

McLennan, P. L., and Abeywardena, M. Y. (2005). Membrane basis for fish oil effects on the heart: linking natural hibernators to prevention of human sudden cardiac death. J. Membr. Biol. 206, 85-102.

McMurchie, E. J., Patten, G. S., McLennan, P. L., Charnock, J. S., and Nestel, P. J. (1988). The influence of dietary lipid supplementation on cardiac beta-adrenergic receptor adenylate cyclase activity in the marmoset monkey. Biochim. Biophys. Acta 937 347-358.

Mozaffarian, D. (2007). JELIS, fish oil, and cardiac events. Lancet 369, 1062-1063.

Mozaffarian, D., Geelen, A., Brouwer, I. A., Geleijense, J. M., Zock, P. L., and Katan, M. B. (2005). Effect of fish oil on heart rate in humans: a metaanalysis of randomized controlled trials. Circulation 112, 1945-1952.

Mozaffarian, D., Jason, H. Y., and Wu, J. H. Y. (2011a). Omega-3 fatty acids and cardiovascular disease. Effects on risk factors, molecular pathways, 
and clinical events. J. Am. Coll. Cardiol. 58, 2047-2067.

Mozaffarian, D., Marchioli, R., Gardner, T., Ferrazzi, P., O’Gara, P., Latini, R., Libby, P., Lombardi, F., Macchia, A., Page, R., Santini, M., Tavazzi, L., and Tognoni, G. (2011b). The $\omega-3$ fatty acids for prevention of postoperative atrial fibrillation trial rationale and design. Am. Heart J. 162, 56-63.

Mozaffarian, D., Lemaitre, R. N., Kuller, L. H., Burke, G. L., Tracy, R. P., and Siscovick, D. S. (2003). Cardiac benefits of fish consumption may depend on the type of fish meal consumed: the Cardiovascular Health Study. Circulation 107, 1372-1377.

Mozaffarian, D., Psaty, B. M., Rimm, E. B., Lemaitre, R. N., Burke, G. L., Lyles, M. F., Lefkowitz, D., and Siscovick, D. S. (2004). Fish intake and risk of incident atrial fibrillation. Circulation 110, 368-373.

Mozaffarian, D., and Rimm, E. B. (2006). Fish intake, concomitants, and human health: evaluating the risks and the benefits. JAMA 296, 1885-1899.

Neubronner, J., Schuchardt, J. P., Kressel, G., Merkel, M., von Schacky, C., and Hahn, A. (2011). Enhanced increase of omega-3 index in response to long-term n-3 fatty acid supplementation from triacylglycerides versus ethyl esters. Eur. J. Clin. Nutr. 65, 247-254.

Niroomand, F., Weinbrenner, C., Weis, A., Bangert, M., Schwencke, C., Marquetant, R., Beyer, T., Strasser, R. H., Kübler, W., and Rauch, B. (1995). Impaired function of inhibitory $\mathrm{G}$ proteins during acute myocardial ischemia of canine hearts and its reversal during reperfusion and a second period of ischemia. Possible implications for the protective mechanism of ischemic preconditioning. Circ. Res. 76, 861-870.

Nodari, S., Metra, M., Milesis, G., Manerba, A., Cesana, B. M., and Gheorghiade, M., and Dei Cas, L. (2009). The role of n-3 PUFAs in preventing the arrhythmic risk in patients with idiopathic dilated cardiomyopathy. Cardiovasc. Drugs Ther. 23, 5-15.

Nodari, S., Triggiani, M., Campia, U., Manerba, A., Milesi, G., Cesana, B. M., Gheoghiade, M., and Dei Cas, L. (2011). n-3 polyunsaturated fatty acids in the prevention of atrial fibrillation recurrences after electrical cardioversion: a prospective, randomized study. Circulation 124, 1100-1106.

Nolan, R. P., Jong, P., Barry-Bianchi, S. M., Tanaka, T. H., and Floras, J.
S. (2008). Effects of drug, biobehavioural and exercise therapies on heart rate variability in coronary artery disease: a systematic review. Eur. J. Cardiovasc. Prev. Rehabil. 15, 386-396.

O'Keefe, J. H., Abuissa, H., Sastre, A., Steinhaus, D. M., and Harris, W. S. (2006). Effects of omega-3 fatty acids on resting heart rate, heart rate recovery after exercise, and heart rate variability in men with healed myocardial infarctions and depressed ejection fractions. Am. J. Cardiol. 97, 1127-1130.

Pouleur, A. C., Barkoudah, E., Uno, H., Skali, H., Finn, P. V., Zelenkofske, S. L., Belenkov, Y. N., Mareev, V., Velazquez, E. J., Rouleau, J. L., Maggioni, A. P., Køber, L., Califf, R. M., McMurray, J. J., Pfeffer, M. A., and Solomon, S. D. (2010). Pathogenesis of sudden unexpected death in a clinical trial of patients with myocardial infarction and left ventricular dysfunction, heart failure, or both. Circulation 122, 597-602.

Raitt, M. H., Connor, W. E., Morris, C., Kron, J., Halperin, B., Chugh, S. S., McClelland, J., Cook, J., MacMurdy, K., Swenson, R., Connor, S. L., Gerhard, G., Kraemer, D. F., Oseran, D., Marchant, C., Calhoun, D., Shnider, R., and McAnulty, J. (2005). Fish oil supplementation and risk of ventricular tachycardia and ventricular fibrillation in patients with implantable defibrillators: a randomized controlled trial. JAMA 293, 2884-2891.

Rauch, B., Colvin, R. A., and Messineo, F. C. (1989). Inhibition of $3 \mathrm{H}-$ quinuclidinyl benzylate binding to cardiac muscarinic receptor by long chain fatty acids can be attenuated by ligand occupation of the receptor. $J$. Mol. Cell. Cardiol. 21, 495-506.

Rauch, B., Niroomand, F., Messineo, F. C., Weis, A., Kübler, W., and Hasselbach, W. (1994). Effect of phospholipid hydrolysis by phospholipase A2 on the kinetics of antagonist binding to cardiac muscarinic receptors. Biochem. Pharmacol. 48, 1289-1296.

Rauch, B., Schiele, R., Schneider, S., Diller, F., Victor, N., Gohlke, H., Gottwik, M., Steinbeck, G., DelCastillo, U., Sack, R., Worth, H., Katus, H., Spitzer, W., Sabin, G., Senges, J., for the OMEGA Study Group. (2010). OMEGA, a randomized, placebo-controlled trial to test the effect of highly purified omega- 3 fatty acids on top of modern guideline-adjusted therapy after myocardial infarction. Circulation 122, 2152-2159.

Rauch, B., Schiele, R. Schneider, S., Gohlke, H., Diller, F., Gottwik, M.,
Steinbeck, G., Heer, T., Katus, H., Zimmer, R., Erdogan, A., Pfafferot, C., Senges, J., OMEGA Study Group. (2006). Highly purified omega-3 fatty acids for secondary prevention of sudden cardiac death after myocardial infarction: aims and methods of the OMEGA-study. Cardiovasc. Drugs Ther. 20, 365-375.

Reiffel, J. A., and McDonald, A. (2006). Antiarrhythmic effects of omega-3 fatty acids. Am. J. Cardiol. 98(Suppl.), 50i-60i.

Saravanan, P., Bridgewater, B., West, A. L., O'Neill, S. C., Calder, P. C., and Davidson, N. C. (2010). Omega-3 fatty acid supplementation does not reduce risk of atrial fibrillation after coronary artery bypass surgery: a randomized, double blind, placebo-controlled clinical trial. Circ. Arrhythm. Electrophysiol. 3, 46-53.

Schuchardt, J. P., Schneider, I., Meyer, H., Neubronner, J., von Schacky, C. and Hahn, A. (2011). Incorporation of EPA and DHA into plasma phospholipids in response to different omega-3 fatty acid formulations - a comparative bioavailability study of fish oil vs. krill oil. Lipids Health Dis. $10,145$.

Shattock, M. J., and Bers, D. M. (1989). Rat vs. rabbit ventricle: Ca flux and intracellular $\mathrm{Na}$ assessed by ion-selective microelectrodes. Am. J. Physiol. 256, C813-C822.

Siddiqui, R. A., Harvey, K. A., and Zaloga, G. P. (2008). Modulation of enzymatic activities by $n-3$ polyunsaturated fatty acids to support cardiovascular health. J. Nutr. Biochem. 19, 417-437.

Siscovick, D. S., Raghunathan, T. E., King, I., Weinmann, S., Wicklund, K. G., Albright, J., Bovbjerg, V., Arbogast, P., Smith, H., Kushi, L. H., Cobb, L. A., Copass, M. K., Psaty, B. M., Lemaitre, R., Retzlaff, B. Childs, M., and Knopp, R. H. (1995). Dietary intake and cell membrane levels of long-chain n-3 polyunsaturated fatty acids and the risk of primary cardiac arrest. JAMA 274, 1363-1367.

Solomon, S. D., Zelenkofske, S., McMurray, J. J., Finn, P. V., Velazquez, E., Ertl, G., Harsanyi, A., Rouleau, J. L., Maggioni, A., Kober, L., White, H., Van de Werf, F., Pieper, K., Califf, R. M., and Pfeffer, M. A. (2005). Valsartan in Acute Myocardial Infarction Trial (VALIANT) Investigators. Sudden deaths in patients with myocardial infarction and left ventricular dysfunction, heart failure, or both. N. Engl. J. Med. 352, 2581-2588.
Tanaka, H., Komikado, C., Namekata, I., Nakamura, H., Suzuki, M., Tsuneoka, Y., Shigenobu, K., and Takahara, A. (2008). Species difference in the contribution of T-type calcium current to cardiac pacemaking as revealed by $\mathrm{r}(-)$-efonidipine. J. Pharmacol. Sci. 107, 99-102.

Verkerk, A. O., den Ruijter, H. M., de Jonge, N., and Coronel, R. (2007). Fish oil curtails the human action potential dome in a heterogeneous manner: implication for arrhythmogenesis. Int. J. Cardiol. 132, 138-140.

Verkerk, A. O., van Ginneken, A. C. G., Berecki, G., den Ruijter, H. M., Schuhmacher, C. A., Veldkamp, M. W., Baartscheer, A., Casini, S., Opthof, T., Hovenier, R., Fiolet, J. W. T., Zock, P. L., and Coronel, R. (2006). Incorporated sarcolemmal fish oil shorten pig ventricular action potentials. Cardiovasc. Res. 70, 509-520.

Wang, C., Harris, W. S., Chung, M., Lichtenstein, A. H., Balk, E. M., Kupelnick, B., Jordan, H. S., and Lau, J. (2006). n-3 Fatty acids from fish or fish-oil supplements, but not $\alpha$ linolenic acid, benefit cardiovascular disease outcomes in primary- and secondary-prevention studies: a systematic review. Am. J. Clin. Nutr. 84, 5-17.

Wang, R. X., Li, X. R., Guo, T., Sun, L. P., Guo, S. X., Yang, Z. Y., Yang, X. J., and Jiang, W. P. (2010). Docosahexaenoic acid has influence on action potentials and transient outward potassium currents of ventricular myocytes. Lipids Health Dis. 9, 39 .

Whelton, S. P., He, J., Whelton, P. K., and Muntner, P. (2004). Meta-analysis of observational studies on fish intake and coronary heart disease. Am. J. Cardiol. 93, 1119-1123.

Xiao, Y. F., Gomez, A. M., Morgan, J. P., Lederer, W. J., and Leaf, A. (1997). Suppression of voltage-gated L-type $\mathrm{Ca}^{2+}$ currents by polyunsaturated fatty acids in adult and neonatal rat ventricular myocytes. Proc. Natl. Acad. Sci. U.S.A. 94, 4182-4187.

Xiao, Y. F., Kang, J. X., Morgan, J. P., and Leaf, A. (1995). Blocking effects of polyunsaturated fatty acids on $\mathrm{Na}^{+}$ channels of neonatal rat ventricular myocytes. Proc. Natl. Acad. Sci. U.S.A. 92, 11000-11004.

Xiao, Y. F., Wright, S. N., Wang, G. K., Morgan, J. P., and Leaf, A. (1998). Fatty acids suppress voltagegated $\mathrm{Na}^{+}$currents in HEK293t cells transfected with the alpha-subunit of the human cardiac sodium channel. Proc. Natl. Acad. Sci. U.S.A. 95, 2680-2685. 
Yan, G. X., Joshi, A., Guo, D., Hlaing, T., Martin, J., Xu, X., and Kowey, P. R. (2004). Phase 2 reentry as a trigger to initiate ventricular fibrillation during early acute myocardial ischemia. Circulation 110, 1036-1041.

Yokoyama, M., Origasa, H., Matsuzaki, M., Matsuzawa, Y., Saito, Y., Ishikawa, Y., Oikawa, S., Sasaki, J., Hishida, H., Itakura, H., Kita, T., Kitabatake, A., Nakaya, N., Sakata, T., Shimada, K., Shirato, K., Japan EPA Lipid Intervention Study (JELIS) Investigators. (2007). Effects of eicosapentaenoic acid on major coronary events in hypercholesterolaemic patients
(JELIS): a randomized open-label, blinded endpoint analysis. Lancet 369, 1090-1098.

Yzebe, D., and Lievre, M. (2004). Fish oils in the care of coronary heart disease patients: a meta-analysis of randomized controlled trials. Fundam. Clin. Pharmacol. 18, 581-592.

Zeghichi-Hamri, S., de Lorgeril, M., Salen, P., Chibane, M., de leiris, J., Boucher, F., and Laporte, F. (2010). Protective effect of dietary n-3 polyunsaturated fatty acids on myocardial resistance to ischemia-reperfusion injury in rats. Nutr. Res. 30, 849-857.

Zhao, Y. T., Chen, Q., Sun, Y. X., Li, X. B., Zhang, P., Xu, Y., and Guo,
J. H. (2009). Prevention of sudden cardiac death with omega-3 fatty acids in patients with coronary heart disease: a meta-analysis of randomized controlled trials. Ann. Med. 41, 301-310.

Conflict of Interest Statement: Bernhard Rauch has no conflicts of interest; Jochen Senges received honoraria for educational presentations from Trommsdorff GmbH \& Co. KG Arzneimittel, Alsdorf, Germany and Pronova Biopharma, Lysaker, Norway

Received: 17 October 2011; accepted: 28 February 2012; published online: 02 April 2012.
Citation: Rauch B and Senges J (2012) The effects of supplementation with omega-3 polyunsaturated fatty acids on cardiac rhythm: anti-arrhythmic, pro-arrhythmic, both or neither? It depends. ... Front. Physio. 3:57. doi: 10.3389/fphys.2012.00057

This article was submitted to Frontiers in Cardiac Electrophysiology, a specialty of Frontiers in Physiology.

Copyright (c) 2012 Rauch and Senges. This is an open-access article distributed under the terms of the Creative Commons Attribution Non Commercial License, which permits non-commercial use, distribution, and reproduction in other forums, provided the original authors and source are credited. 